\title{
Roles and Capabilities of Enterprise Architecture in Big Data Analytics Technology Adoption and Implementation
}

\section{Yiwei Gong' and Marijn Janssen²}

\author{
${ }^{1}$ Wuhan University, School of Information Management, Wuhan, P. R. China, yiweigong@whu.edu.cn \\ ${ }^{2}$ Delft University of Technology, Faculty of Technology, Policy and Management, Delft, the Netherlands, \\ M.F.W.H.A.Janssen@tudelft.nl
}

Received 8 January 2019; received in revised form 6 November 2019; accepted 10 December 2019

\begin{abstract}
Organizations are attempting to harness the power of big data analytics. Enterprise architecture can be used as an instrument to integrate big data analytics into the existing IT landscape and enabling the development of capabilities to create value from these technologies. Yet, there is limited research about the role of enterprise architecture in adopting big data analytics. This paper explores enterprise architecture roles and capabilities for the adoption of big data analytics by conducting a qualitative case study at the Dutch Tax and Customs Administration. The first attempt to adopt big data analytics was focused on integrating analytics into the current complex IT landscape, but this encountered many challenges and resulted in slow progress. To overcome these challenges, a separate department was created to quickly harness the potential of big data analytics. Enterprise architecture was used for impact analysis and to create a transition process. The findings suggest that enterprise architecture was used in different ways at the various stages of adoption and implementation, requiring different roles and a different set of capabilities. Enterprise architecture was found to be contingent on the type of technology and the situation at hand. We recommend more research into the role of the context in enterprise architecture research.
\end{abstract}

Keywords: Big data, Big data analytics, Enterprise architecture, Adoption, Flexibility, Dynamic capabilities, E-government 


\section{Introduction}

Big data technology entails collecting and processing large volumes of data from a variety of sources [17]. Modern organizations are data intensive by nature, and the use of Big Data Analytics (BDA) can provide new insights. BDA has a major influence on the way organizations operate and results in efficiency improvements and innovation [3]. For example, by creating profiles of people to target customers better [15], BDA can help financial organizations detect and combat fiscal fraud more successfully [14], or BDA may also enable better decision-support information, more informed decision-making and customized approaches [59]. BDA has been recognized as being essential for organizations [28]. However, in comparison with BDA technologies and applications, considerably less research attention has been paid to organizational strategies to successfully embrace BDA in organizations [43].

Adopting and implementing BDA has been challenging for large organizations [25]. BDA technologies might need to be made fit for a particular situation, and the infrastructure of an organization must be able to support the use of new technologies [29]. However, this need to integrate new tools and technologies into the current IT landscape can be supported by Enterprise Architecture (EA) [7]. Furthermore, there might be a need for changes in the business processes and responsibilities. EA could help to integrate BDA in the current landscape. Although the potential of EA is clear, to the best of our knowledge, there has been no research conducted to understand the roles of EA in BDA adoption.

EA has no uniform definition [53]. One definition of EA is 'a coherent whole of principles, methods, and models that are used in the design and realization of an enterprise's organizational structure, business processes, information systems, and infrastructure' [36] , p. 3. EA can improve sharing and integration of IT resources across an enterprise [9], create and enable interoperability, guide the design of new infrastructures and enable transformation [2], [32]. Thus, it allows organizations to proactively respond to disruptive innovations by identifying and analyzing the execution of change that achieves the desired business vision and outcomes [24]. EA can be used to integrate new technology developments, such as the cloud [21] and bring your own device (BYOD) [51], into existing organizations. Despite its significance, limited attention has been paid to the possible roles that EA can play in helping organizations to adopt and implement BD.

The objective of this paper is to analyze the roles of EA and dynamic capabilities needed in BDA adoption and implementation in large public organizations. The motivation for this study is to understand the challenges encountered by organizations in BDA adoption, and whether and how EA can be used to overcome these challenges. Our focus is on large organizations, as they often make use of EA to manage their IT landscape. A comprehensive case study was conducted in the Dutch Tax and Customs Administration in a period of 5 years, observing and analyzing their strategy and its effect on BDA adoption. The reason for selecting this case was that much information was available publicly and the organization is viewed as a frontrunner in BDA applications. The multiple sources enabled us to gain a deep understanding. This study may offer guidance to other large organizations using many big data sources for various purposes in relation to their own future BDA initiatives.

The paper is structured as follows. In Section 2, we briefly discuss the background of the relationship between BDA adoption and implementation and EA. We review the typical challenges and the potential roles and dynamic capabilities of EA to deal with them. Subsequently, the research method is explained in Section 3. In Section 4, we present an overview of the case study. In Section 5, we discuss the case study findings and their practical implications, while Section 6 presents our conclusions.

\section{Background}

In this section the BDA adoption challenges as found in the literature are reviewed. Next possible roles and capabilities of EA are identified.

\subsection{BDA Adoption Challenges}

EA should help to overcome BDA adoption challenges and understanding these challenges requires to understand the roles and capabilities of EA. Traditionally, organizations use well-structured data that is collected for a certain purpose and stored, often in relational databases. Basic queries can be executed based on this data. Over time, the number of databases, the variety of formats and the amount of data has grown into what is now called BDA [14]. The use of BDA enables organizations to go beyond mere utilization of each database and data set in isolation. Data sets are now combined or integrated to achieve new insights.

While many studies have enhanced our understanding of the BDA phenomenon, most emphasize the technical dimension of BDA and understate the importance of the organizational dimension, which is equally important to reap the benefits of BDA [28]. Unlike the more tangible BDA technical capabilities, those in the organizational dimension are often intangible and concern the collaboration and strategy of the organization [13]. Organizational capabilities address whether organizations possess the required capacities to use BDA and to create value from it for the 
organization [35]. If these organizational capabilities are not sufficient, the benefits generated from the use of BDA will be limited [35]. In the current climate, BDA is expected to create value for organizations. However, realizing such value is much more difficult, and many challenges will be encountered during the adoption of BDA technologies and the implementation of BDA application [26], [59]. For example, based on a systematic literature review, Sivarajah, et al. [59] identified 18 BDA challenges, classifying them into three main categories: data, process and management. Data challenges relate to the characteristics of the data itself, for example data volume, variety, velocity, veracity, volatility, quality, discovery and dogmatism. Process challenges relate to a series of how questions: how to capture data, how to integrate data, how to transform data, how to select the right model for analysis and how to provide the results. Management challenges relate to the management strategy or policy constraints in BDA adoption, for example privacy, security, governance and ethical aspects. Sivarajah, et al. [59] found that different sectors and organizations will face different types of challenges and that there is a need for more research using in-depth case studies in organizations in different sectors.

In the literature, only a limited number of articles have investigated the management challenges of BDA adoption. The remainder mainly focus on the technologies or benefits of BDA, the introduction of a certain BDA application in a sector, or discuss the data and process challenges. Based on our literature survey, Table 1 presents the main management challenges of BDA adoption to which organizations need to respond strategically.

Table 1: Typical management challenges of BDA adoption for large organizations

\begin{tabular}{|c|c|}
\hline Challenges & Description \\
\hline $\begin{array}{l}\text { Fragmented and siloed } \\
\text { applications [25], [33], [34], [38], } \\
\text { [59] }\end{array}$ & $\begin{array}{l}\text { - Enormous amount of data is stored in legacy databases. } \\
\text { - Problems occur when trying to make BDA applications work with these } \\
\text { traditional mainframes and databases. } \\
\text { - There are many siloed departments owning different types of data. The } \\
\text { institutional setup and routine of sharing and collecting data often } \\
\text { poses a major obstacle. }\end{array}$ \\
\hline Privacy $^{*}[19],[55],[65],[68]$ & $\begin{array}{l}\text { - Organizations are faced with the obligation to manage their need for } \\
\text { customer information and the customer's need for privacy. } \\
\text { - Data protection regulations and privacy law restrict organizations in } \\
\text { their use of data. }\end{array}$ \\
\hline $\begin{array}{l}\text { Management capabilities [25], } \\
\text { [35], [50], [59], [70] }\end{array}$ & $\begin{array}{l}\text { - This concept describes the organization's use of BDA linked to IT } \\
\text { infrastructure, data governance and data science expertise. The } \\
\text { organization needs to possess the requisite capacities before making } \\
\text { use of BD. } \\
\text { - Organizations need management capabilities to facilitate data sharing } \\
\text { in BDA applications and enhance operations performance. }\end{array}$ \\
\hline $\begin{array}{l}\text { Authority and legitimacy [34], } \\
\text { [40], [41], [69] }\end{array}$ & $\begin{array}{l}\text { BDA applications need authority to access databases and data records } \\
\text { and legitimacy to use them. } \\
\text { - Managers need authority to facilitate BDA actions, and legitimacy to } \\
\text { drive organizational change. }\end{array}$ \\
\hline
\end{tabular}

${ }^{*}$ Many studies mentioned privacy as a BDA challenge. To avoid of confusion, only those focusing on privacy issues from an organizational or strategic perspective are listed in the table.

Many systems are fragmented and have developed without considering the need to exchange information. Siloed applications are often encountered in many large organizations, or when different organizations start to work with each other. Siloed processes can originate from legal requirements, in which personal data cannot be shared due to data protection laws, or from a rigid institutional setup and routine that pose major obstacles [25]. Organizations such as government agencies or departments are often reluctant to share data that is considered to be proprietary to them. Furthermore, isolated IT systems complicate the integration of complementary data within the organization [34]. This results in a need to break down the silos or to integrate data and applications. Furthermore, addressing the silo problems consequently requires the organization to balance among integration and privacy protection, compliance and/or accountability.

The requirements for data protection found in regulatory frameworks such as the General Data Protection Regulation (GDPR) determine the way in which BDA can be used by organizations, with privacy laws restricting the collection, sharing or utilization of personal data [25]. At the same time, additional data from citizens, the neighborhood or the community is needed to offer personalized services or better governance, for example in relation to traffic control, energy consumption, disease prevention, public security, personalized services and so on. Ultimately, there is a need to find a balance between privacy protection and other values or general interests [19]. 
Organizations need management capabilities to handle BDA and to realize its expected outcomes and may address this by employing staff, creating agencies and building new operational business processes. Management capabilities relates to the organizational capacity to make use of BD, and it is often assessed in terms of BDA readiness [25], [35]. The concept of BDA readiness focuses on the organizational alignment and capabilities in connection to BDA. From an intra-organizational perspective, alignment refers to whether BDA use is a good fit with the organization's structure and main activities. From an inter-organizational perspective, this is also referred to as engagement capacity, which captures the ability of the organization to digitally interface with external groups and organizations to make use of BDA [70].

In addition to data protection, organizations must address security and compliance requirements when using data. However, unlocking the full potential of BDA first requires the authority to develop knowledge and skills and to allow innovative use of data [40]. In other words, to facilitate BDA adoption and drive organizational change, managers might first need to legitimate their actions [41]. The use of BDA can improve services, but can also undermine trust in organizations, as customers question the legitimacy of providing or allowing access to sensitive data [44]. These kinds of concerns might be addressed at the legislative level to create an appropriate balance. However, for public organizations, it is more important to ensure the accountability of their business processes and decision-making. This might entail that they ensure the organization is able to check the compliance of their service provision and decision-making processes with the changing legal environment.

The above management challenges for organizations indicate the special concerns about BDA adoption. At the same time, however, limited knowledge about BDA adoption from an organizational perspective has been reported in the literature. Organizations are postponing decisions on BDA adoption because they are uncertain about how these challenges could be addressed to take advantage of BDA [35]. It is, therefore, desirable to investigate those challenges and how they might be overcome with the help of EA.

\subsection{EA Roles and Capabilities for BDA Adoption}

Along with the adoption of new information technology, the complexity of corporate IT environments has been growing steadily. The growth of IT complexity often leads to various problems, such as higher operational risks and costs for maintenance or operation, and insufficient flexibility with regard to changes in business strategy and processes [56]. In practice, EA provides big-picture planning and understanding of the interdependences between various IT components, which is of critical importance in solving these problems [60], [62]. EA provides a range of capabilities to deal with technology aimed at improving organizational performance [53]. EA captures a range of aspects, including business processes, data models, applications and technical infrastructure [64]. EA can have various roles in organizations for managing business and IT [27]. Table 2Table 3 summarizes the roles of EA as discussed in the literature. Usually, EA consists of descriptive and prescriptive models to understand the current situation and what the desired situation should look like [31]. The architecture models should help to improve the relevant parts of the organization (i.e. the business process, data, application and infrastructure) and take into account the relationships as they are depicted by the architecture. In this way, a coherent picture is created. This approach assumes that the situation desired can be blueprinted to some extent and that the relationship with the current situation is clear. Another view of EA considers it a process in which the focus is on managing the improvement process supported by architectural instruments [61].

Table 2: The roles of EA in organizations

\begin{tabular}{|c|c|c|}
\hline Roles of EA & Description & Literature \\
\hline Dealing with complexity & $\begin{array}{l}\text { Manage complexity and risks due to various factors such as } \\
\text { technology, size, interface, context and stakeholders }\end{array}$ & $\begin{array}{l}{[4],[23],[47],} \\
{[48]}\end{array}$ \\
\hline Facilitating reuse & Enable reuse of IT components and services & $\begin{array}{l}\text { [22], [32], [42], } \\
{[47]}\end{array}$ \\
\hline Enabling interoperability & $\begin{array}{l}\text { Provide guidance for development in the existing situation and } \\
\text { ensuring interoperability }\end{array}$ & [49], [74] \\
\hline Client orientation & crease client satisfaction or gain more customers & [32], [37] \\
\hline Creating flexibility & Increase flexibility to deal with changes in business or IT & [11], [18], [42] \\
\hline $\begin{array}{l}\text { Adhering to public values } \\
\text { such as privacy }\end{array}$ & $\begin{array}{l}\text { Ensure legal compliance, such as ensuring information } \\
\text { protection according to privacy laws }\end{array}$ & [32] \\
\hline $\begin{array}{l}\text { Facilitating } \\
\text { communication }\end{array}$ & $\begin{array}{l}\begin{array}{l}\text { Improve the communication required to align different } \\
\text { stakeholders }\end{array} \\
\end{array}$ & $\begin{array}{l}{[1],[4],[47],} \\
{[58],[67]}\end{array}$ \\
\hline Impact evaluation & $\begin{array}{l}\text { Evaluate potential future solutions to understand the possible } \\
\text { impact }\end{array}$ & [23], [39], [58] \\
\hline Decision-making support & $\begin{array}{l}\text { Support decision-making about IT investments, design of new } \\
\text { infrastructures, and capabilities development }\end{array}$ & $\begin{array}{l}\text { [45], [54], [62], } \\
\text { [66] }\end{array}$ \\
\hline Migration strategy & $\begin{array}{l}\text { Develop the migration plan for transitioning from the current to } \\
\text { the future situation }\end{array}$ & [32], [62] \\
\hline
\end{tabular}


Despite its significance, there is limited work on the role of EA in supporting new technology adoption. The exceptions include studies investigating EA's effect on the organizational adoption of service-oriented architecture (SOA) [5] and those pointing to EA's importance in cloud computing adoption [21]. These studies are focused on technology that are primarily changing the IT functions, however, BDA is used by the businesses directly to create value for the organizations. This requires complex interactions between the IT and Business parts of an organization. In addition, some earlier work has investigated the use of EA in technology adoption in a more general manner; for example, looking at the use of EA artefacts in IT acquisition management by providing a description of the organization and its requirements for vendors [10]. However, existing studies have often focused on the benefits of EA rather than an analysis of how EA can be used to adopt new technology. For example, in one study of IT acquisition, EA artefacts were purely regarded as background material [46]. The limited findings in the literature reveal the knowledge gap in understanding the role of EA in new technology adoption, and especially in the adoption of BDA.

Management practice and research is increasingly incorporating new technology adoption into EA-related issues [71]. EA can be used to develop a common understanding or interpretation of existing and new technologies, and as such could be used as a tool by organizations to understand the potential and feasibility of new technologies [8]. Shanks, et al. [57] suggest that EA will enable organizations to adopt new technologies more successfully and consequently lead to quicker response to changes in customer demand by offering relevant new products and services and better strategic alignment between business and IT in contrast to competitors. However, EA-based benefit realization for organization is a complex process and is influenced by EA maturity and capability [12]. EA is still a rather young and immature discipline, for which no common practice has yet emerged [56]. In practice, different organizations have often employed different approaches, depending on their strategies and EA capability.

EA should create the necessary capabilities for organizations to adopt BDA technology. According to Winter [72], an organizational capability is a high level routine (or collection of routines) that, together with its implementing input flows, confers upon an organization's management a set of decision options for producing significant outputs of a particular type (p. 991). In contrast with ordinary (or operational) capabilities that focus on ordinary routines, dynamic capabilities focus on the organizational strategic routines [20] and govern the rate of the change of ordinary organizational capabilities [16]. Teece, et al. [63] define dynamic capabilities as the ability to integrate, build, and reconfigure internal and external competences to address rapidly changing environments (p. 516). Dynamic capabilities are needed to integrate BDA in the organization and reconfiguring is needed to learn from the experiences. From this lens, EA is an enabler of dynamic capabilities of the organization. The better the EA function is developed the better the capabilities of an organization to adopt new technology. While EA is expected to have an impact and evolve continuously in the BDA movement, how EA can be used to facilitate effective applications of BDA is still an open question [52]. There is a void in the literature addressing the roles and capabilities for adopting BD. This paper attempts to explore this question by addressing the roles and dynamic capabilities of EA in BDA adoption.

\section{Research Approach}

Although there is much work on BDA and EA, there is limited work that combines these fields. A longitudinal case study research methodology was considered suitable for our study as we were interested in both organizational and technical issues [6], understand the various roles of EA over time [4] and in studying the phenomenon in its natural setting [73]. Using a longitudinal case study, we intended to gain an understanding of the successful and unsuccessful attempts at BDA adoption and in this way gain a deeper understanding of the role of EA in BDA adoption and implementation in large organizations, and specifically in the roles and capabilities. The following research questions guided our study:

\section{What are the challenges in BDA adoption and implementation for the organization?}

\section{What are the roles and dynamic capabilities of EA in BDA adoption and implementation?}

\section{How should EA be used to facilitate BDA adoption and implementation?}

As the literature indicates that different organizations encountered different types of challenges, the first research question addresses the challenges that our case study organization faced. This information is the basic input for identifying and analyzing which challenges could be addressed by EA according to empirical evidence. The second research question concerns the dynamic capabilities that are enabled by EA during BDA adoption and implementation. By answering this question, the benefits of EA for BDA adoption and implementation could be discovered. Consequently, the third research question addresses how to realize those EA benefits and what experience and implication could be generated from the case study.

To collect the data, a large administrative organization was investigated over a relatively long period of time. As the main data collection instruments, interviews, reading available materials and observation were used. This allowed us to observe the considerations and the steps taken in BDA adoption and implementation, as well as the challenges the organization encountered. To this end, we will describe the background and the attempts to introduce BDA. These BDA implementation efforts were analyzed over time by conducting interviews and analyzing documents 
capturing the history. Interviews were conducted with people in the administrative department, as well as enterprise architects, competence center managers and an external consultant. As persons left and entered the organizations the same people could not be interviewed every time. In total 9 different persons were interviewed resulting in 15 interviews altogether. The efforts started in 2012 and our initial interviews were held in 2014, followed by interviews in 2016 and 2018. The times followed the major events of 1) internally driven strategy, 2) externally driven strategy and 3 ) the integration of BDA in the organization. Table 3 presents an overview of the interviewees in each of the above phases.

Table 3: Overview of the interviewees per phase

\begin{tabular}{|l|l|l|}
\hline 1. Internally driven strategy - 2014 & $\begin{array}{l}\text { 2. Externally driven strategy - } \\
2016\end{array}$ & 3. Integration strategy -2018 \\
\hline $\mathrm{ClO}$ & ClO & ClO \\
Head of Business Intelligence and & Chief Analytics Officer & Enterprise architect \\
analytics & Enterprise architect business & Head of Innovation \& strategy \\
Enterprise architect & intelligence Data \& Analytics experts \\
Innovation officer & Strategic advisor & \\
\hline
\end{tabular}

\section{Case Study}

The Dutch Tax and Customs Administration is responsible for collecting tax revenue in the Netherlands. This provides a legal basis to use data to improve the assessment of tax files and the collection of taxes. The tax organization has several geographical locations and a huge IT department. There is a separate EA group that develops, updates and maintains their architectures. This group is positioned close to the policymaking department and is intended to assist in the realization of policies that are feasible to implement. Nevertheless, architects are in different locations and they have different focuses. The Open Group ArchiMate standards have been adopted to model the architecture. There is a vast library of ArchiMate models available describing the various aspects of the architecture. Formal models, principles and documents are available that have been approved by an architecture review board (ARB). Once approved they should be used or it should be explained why they cannot be used. The models and other documentations enable the management of the architecture and the migration towards new situations.

The organization has many big data sources available, but they were hardly used. Furthermore, there are many big data sources outside the organization which can potentially be used. These can be open data, but also data of other public organizations about properties like houses and cars and income information from social security, and private organizations like selling/buying of products, and also financial information. Some of the information had been already used in the operational processes to pre-fill tax forms. In various departments, big data has the potential to improve their business. There are departments that focus on a certain type of tax (VAT, Income etc.), and departments that focus on citizens or businesses. Although their needs are different, many of these departments are in need of the same big data sources.

In the internally-driven strategy phase, the organization initiated various BDA programs to improve their administrative processes. Various departments reserved budget and hired external staff to explore the potential of BDA. They had high ambitions to reduce the number of staff by utilizing BDA to detect tax evasion and fraud automatically. Their strategy was to avoid the development of new and risky large systems and their focus was on creating a coherent landscape in which data can be exchanged. Data was stored in various places in the organization and external data sources were in use. The internal procedures and mechanisms were to be followed for innovation, but the ARB had to approve new software and principles, which delayed the process. The EA could be used to inform the changes, however, they were lacking BDA knowledge. One interviewee commented that the emphasis shifted towards competing between departments, instead of collaboration, as everybody wants to present their innovation as the killer application and claims that the architecture is not suitable.

The initial adoption strategy was to explore the opportunities internally and subsequently exploit them, as shown by the internally driven strategy arrow in Figure 1. Exploration is associated with innovation, search, discovery and experimentation, while exploitation is generally associated with gradual improvement, refinement and efficiency [30]. As manual control of every tax file has become impossible, the idea was that BDA would enable a move towards a risk-based approach, in which existing data would be used to create risk profiles of citizens and businesses. For this innovation, various departments began making better use of their data. Most departments educated some of their current staff to understand and analyze the data, while other departments hired specialists in this area. Although this adoption strategy resulted in progress, the efforts proved not to be effective, given the high ambitions of management, which wanted more rapid progress. An interviewee stated that departments should work together to avoid duplication of efforts and high costs. Only when they work together will data quality and reliability be accomplished at acceptable costs. 


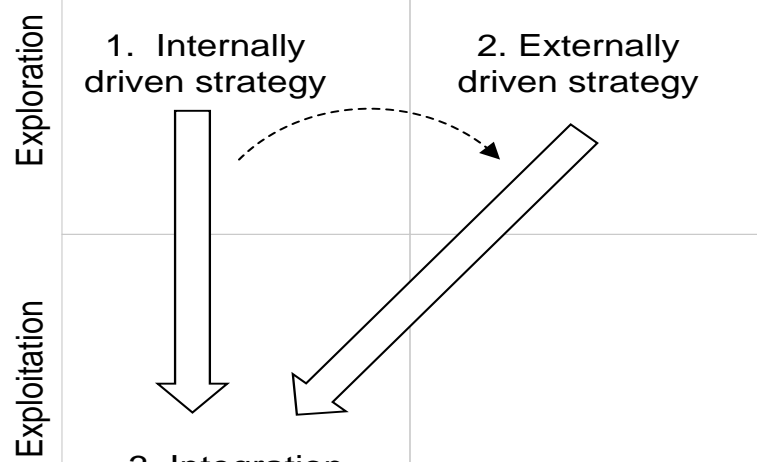

\section{Integration}

Internal External

Figure 1: Shift in BDA adoption strategy from internally to externally driven approach

Therefore, at the next stage, named externally-driven strategy phase, a separate department running major BDA projects was created to implement a new strategy, as visualized by the externally driven strategy arrow in Figure 1. The second strategy was adopted to progress more quickly without being constrained by existing institutionalized patterns and procedures. This department was operated separately from all the other departments in the tax organization, and directly led by the management board. To obtain BDA analytical skills, this department hired experts who had a proven record in using BDA in other domains. The disadvantages were a poor connection between this department and other departments of the organization and limited knowledge about the core activities. This department collected the data by extracting it from the existing systems of the tax organization and importing it into its own systems. In addition, external sources, such as social media, were used to enrich the data; for example, to detect trading activities that were not reported. Subsequently, an analysis was made without being bound by the organizational structures. One interviewee told that this resulted in innovation without considering the tacit knowledge and complying with legislation, all lessons from the past are neglected. The use of their own systems, irrespective of the current architecture and standards, resulted in quick development but also in more heterogeneity. Although the second strategy appeared to accelerate exploration and the development of BDA applications, the actual exploration took more time. The use of the new BDA applications encountered resistance in the organization and the new applications were also developed without considering the existing landscape. This made it difficult to integrate the innovative BDA applications into the existing landscape and modifications of the existing landscape were required.

In the third phase, integration, the BDA efforts were integrated in the organization. This is shown in Figure 1 in the quadrant of exploitation in the internal organization. A clearer view on where BDA could be used was developed over time. Agile development teams were created and worked on BDA development programs, by teaming up with tax experts and others. EA provides a value-added role and helped to create a platform for using data. Despite some clear technology choices and support the data stored in silos remains. This allowed analysis to be conducted and rapid feedback to be gained. However, there were some issues. Finding and collecting the data proved to be a cumbersome process. The data had various qualities which sometimes made it difficult to use. In addition, understanding the domain was found to be a condition for being able to interpret the data. Finally, as the team was separated from the other parts of the tax organization, an awareness of norms and values that should be adhered to was lower. This resulted in the violation of the data protection act, with data collected and stored in a huge data warehouse. The latter are also more vulnerable to cybersecurity attacks.

\section{Findings and Implications}

The case study provides insight into the use of EA for BDA adoption and implementation. This section presents and discusses our findings and their implications with regard to the three research questions.

\subsection{BDA Challenges and the Use of EA}

The case study presents a change in BDA adoption strategy, from an internally driven to an externally driven approach over time. Both strategies needed EA to support BDA adoption and development. By examining the type of management challenges, listed in Table 1 above, we found that the change in strategy introduced different management challenges to the organization. As different challenges were encountered, the use of EA shifted, along with the change in BDA adoption strategy. The bases of both strategies, the BDA challenges in the organization and an overview of the use of EA are shown in Table 4. The BDA challenges are summarized in a map with the management challenges of BDA adoption from the literature (Table 1). 
Table 4: BDA Adoption challenges and the use of EA

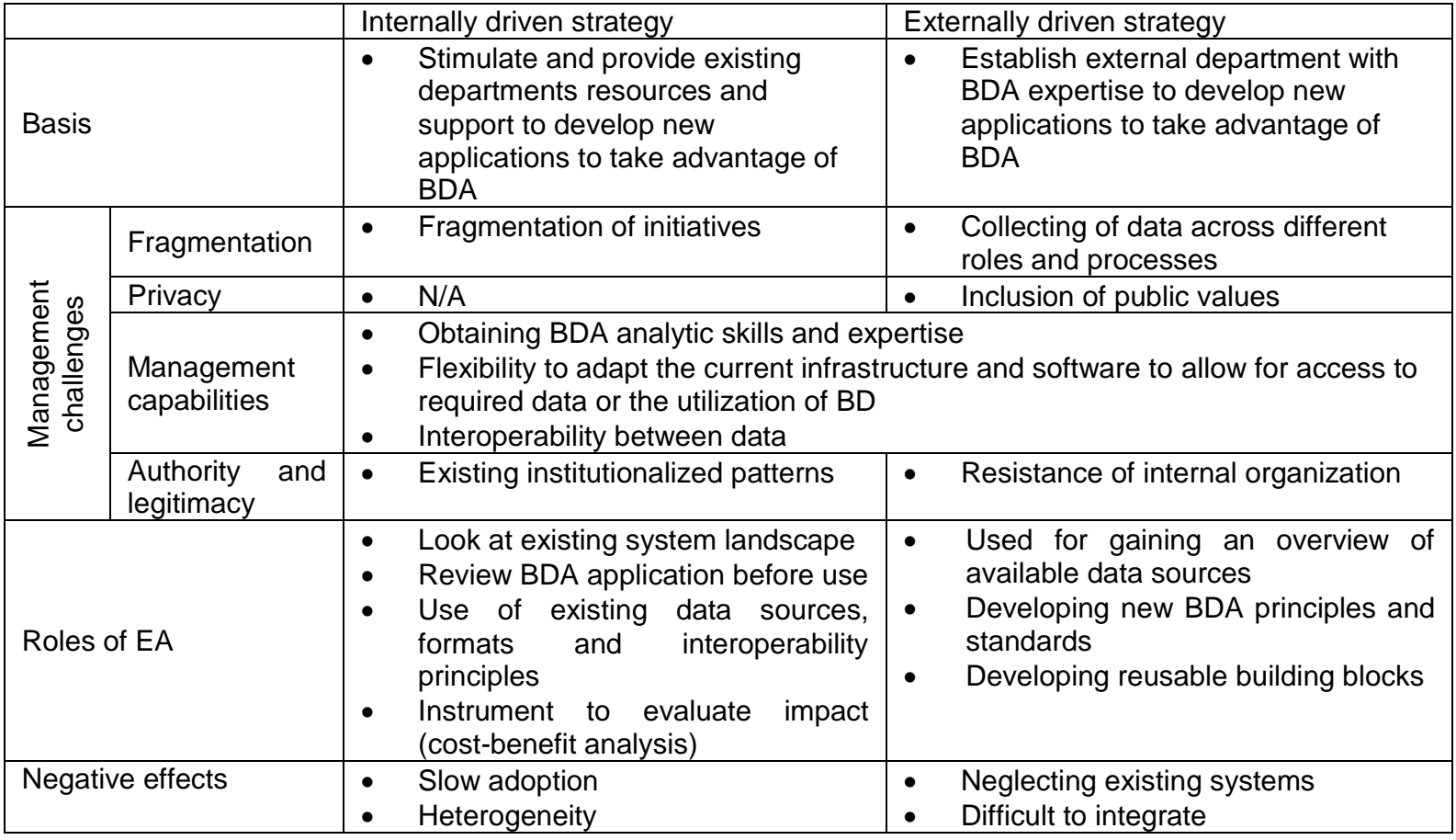

In the internally driven strategy, the idea was to facilitate bottom-up initiatives and to gradually incorporate the results of the initiatives into the EA. The bottom-up initiatives were expected to develop software components and introduce new processes and procedures for dealing with BD. The departments of the tax organization employed EA to understand the existing IT landscape and how the existing systems that they used connected to the infrastructure. This allowed them to review implementation feasibility of the proposed BDA application before use. In addition, EA indicated the existing data sources that could be used by the proposed BDA application, while the interoperability principles determined the system requirements. To some extent, EA also enabled the evaluation of the proposed BDA application in a cost-benefit analysis.

At first, the tax organization expected this strategy to allow for the integration of BDA applications within the existing IT landscape and thus present a highly cost-beneficial solution through the reuse of existing resources. However, the initiatives were found to be overly diverse and did not create cross-departmental applications. They were proven to be insufficiently advanced to provide undisputed input into the EA. Moreover, the existing departments did not have the capabilities to make use of this advanced technology. In addition, it was unclear how the existing systems should be updated and how data governance should be dealt with. Overcoming these challenges was very time-consuming and the EA group and ARB found themselves overworked.

The literature suggests that EA should be used as a blueprint to specify a certain implementation or provide guidelines for implementation on a higher level [4], [46]. However, the assumption that the desired situation can be blueprinted to integrate BDA was not found valid in our case. Only a long-term vision can be developed, but there are so many complexities and changes that a detailed description of the future situation is not possible. Complexities were found at different levels, which proved to make it too complicated to develop a blueprint in which BDA could be integrated into the existing structure. The infrastructure was not able to handle the large amount of data, data with various formats proved not to be interoperable and people did not have the skills and expertise for BDA analysis. These issues needed to be resolved and understood before a blueprint could be made to integrate BDA use into the current infrastructure.

The above challenges resulted in difficulty in integrating BDA into the current IT landscape. This resulted in the creation of a separate department, which operated independently from the existing organization. BDA experts were hired and used to create this department. New technology was used, which was different from the conventional technologies. This effort came with the creation of added value applications, such as dynamic monitoring of the economic activities of people and organizations who did not pay their taxes. Based on this strategy, EA was used as a collection of existing standards and data sources. This allowed the new BDA principles and standards to be considered alongside the existing ones. The reusability of BDA applications was also considered by using EA as the input for deriving requirements from different departments.

Separation from the current IT landscape made the process of BDA development faster than the first strategy. However, this also resulted in the creation of a separate domain, which could not be integrated with the existing IT landscape. This neglect of the existing systems created another kind of silo, in which the lack of collaboration among 
people with different roles and across processes hindered the collection of data. Furthermore, as most of the newly hired people were not familiar with the tax organization, the new systems did not adhere to the required norms and public values. In particular, the storage of all the data, with the ability to link this to person, was found to be in violation of the data protection act. There was also friction between the departments in charge of the collection of the data and the external department conducting data analytics.

In the third phase, the importance of systems integration and data governance has been realized. EA is expected to facilitate the integration of processes and systems and enable data management across departments. In a comparison with the first phase, the organization encountered the similar issues regarding the adaptation of infrastructure and data interoperability. This implies the need of comprehensive capabilities beyond the choice of BDA adoption and implementation strategies.

\subsection{Developing Dynamic Capabilities}

Organizations are often uncertain about what dynamic capabilities are required for BDA adoption and implementation before they start their BDA initiatives [35]. BDA requires new capabilities that are not readily available in the organization. Developing new BDA applications requires that staff should be able to program, analyze the data, have knowledge of statistics and be a good communicator. These capabilities can either be developed in-house through training and experimentation or can be bought on the market and subsequently internalized. Knowledge transfer and information flows from both internal and external sources play an important role in the creation of dynamic capabilities.

One way the tax organization could overcome the challenges encountered in BDA adoption and implementation was to develop a new set of capabilities that it did not previously possess. These capabilities (see Table 5) range from the strategic to the technical. Lacking these capabilities makes it difficult to realize the benefits of BD. In particular, the many changes that were needed could not be dealt with by the organization. Multiple interviewers indicated that the organization did not have sufficient dynamic capability to deal with all the changes at the same time.

Table 5: An overview of dynamic capabilities needed for BDA adoption and implementation in the tax organization

\begin{tabular}{|c|c|}
\hline Category & Capabilities needed \\
\hline Technology & $\begin{array}{l}\text { - to share BDA using a basic infrastructure } \\
\text { - to define standards for BDA exchange } \\
\text { - To protect personal data } \\
\text { - To use data analytics software to analyze BD } \\
\text { - To identify the changes in systems needed }\end{array}$ \\
\hline Collaboration & $\begin{array}{l}\text { - To create a collaborative network to gain access to data } \\
\text { - To use BDA to create value } \\
\text { - To govern the use of BDA } \\
\text { - To create BDA and data analytics expertise }\end{array}$ \\
\hline Strategy & $\begin{array}{l}\text { - To understand BDA opportunities for the organization } \\
\text { - To gain top management support }\end{array}$ \\
\hline
\end{tabular}

To overcome the challenges of flexibility and interoperability, the organization is required to fundamentally improve its infrastructure and software technology. In the case study, the current EA documents informed BDA developers about the location and content of data, but this was found to provide limited help in integrating BDA into the existing infrastructure and software. The findings suggest that current infrastructures might not be suitable for integrating BDA, and substantial changes are needed. The main question for the organization is therefore not how to use current $\mathrm{EA}$ documents to manage the integration of $\mathrm{BDA}$, but how to redesign the infrastructure to make it suitable for BDA implementation, as well as develop a migration plan for it by making use of EA.

Standardization is also important for enabling efficient data exchange and reuse, and consequently facilitates interoperability. Various data formats were documented by EA files as input for defining BDA standards at the organizational level. However, standardization is still quite a difficult job and has uncertainties, as it is not only affected by the current use of data within an organization but also by changes in industrial or national standards, and 
the possible use of BDA in the future. Moreover, even when infrastructure and standardization are adjusted for the use of BD, people need sufficient BDA skills to be able to realize the benefits.

Furthermore, to avoid fragmentations, the BDA value-creation process should be negotiated and designed in a collaborative network, allowing further access to and usage of data. Data governance that ensures the quality of data and the appropriate use of it is important to protect privacy and ensure legitimacy, thereby maintaining a social structure suitable for BDA development. This goes beyond the current use of EA for documenting who is doing what in a business process. The new capabilities for collaboration will allow the organization to redesign the business processes across different departments from a value-creation perspective, rather than simply connecting existing processes.

Finally, leadership support is essential in BDA implementation to ensure authority. Public organizations often create institutional structures through the division of their business and services. The use of BDA often does not fall to a single department, but has an impact on a larger scale, creating new insight for the whole organization. Top management could use EA as input to redesign the organizational structure and make appropriate adjustments to existing institutionalized patterns to provide authority for BDA implementation. This means top management is able to understand and can make decisions based on freeing up resources, and support the use of BDA in a global and long-term perspective.

Possessing the above capabilities allows an organization to reconsider the role of EA in BDA adoption and implementation. The case study implies that given sufficient capabilities, EA could play a more important role in BDA adoption and implementation. This will be discussed in the following section.

\subsection{Roles of EA in BDA Adoption and Implementation}

The investigation of different BDA adoption strategies gives us an insight into the effect of using EA in BDA adoption. However, this only reflects a narrow view on EA functions, whereas EA had an even greater role in BDA development. To understand the potential roles of EA in BDA adoption and implementation, we confronted the roles of $E A$ as found in the literature and the findings of this case study. EA roles were used in various ways, as shown in Table 6 . The possible roles of EA as found in the literature are outlined in the left-hand column. The roles found in our case study are listed in the right-hand column. The table clearly shows that multiple roles of EA were of importance. Only client orientation and decision-making support were not found to be important in the case study: although BDA helps to better understand clients, EA was not used to enable this; and the decision to use BDA had already been made without the support of EA. Furthermore, the roles of EA changes over time and needs to be appropriate. This suggests that EA should not be viewed as a one size that fits, but should be customized and the roles are context dependent.

Table 6: Overview of the roles of EA in BDA adoption and implementation

\begin{tabular}{|l|l|}
\hline Roles of EA & Roles found in the case study \\
\hline $\begin{array}{l}\text { Dealing with } \\
\text { complexity }\end{array}$ & The ability to decompose BDA effort into manageable parts was a key aspect \\
\hline Facilitating reuse & $\begin{array}{l}\text { Identification and development of reusable building blocks for collecting and } \\
\text { processing BDA }\end{array}$ \\
\hline $\begin{array}{l}\text { Enabling } \\
\text { interoperability }\end{array}$ & $\begin{array}{l}\text { Interoperability was perceived as a long-term problem. Initially, manual activities were } \\
\text { performed to enable transfer of data to and from systems. EA provided input for } \\
\text { defining BDA standards at the organizational level to facilitate interoperability }\end{array}$ \\
\hline Client orientation & Not identified \\
\hline $\begin{array}{l}\text { Creating flexibility } \\
\text { variety of BDA applications }\end{array}$ \\
\hline $\begin{array}{l}\text { Ensuring public values } \\
\text { such as privacy are } \\
\text { adhered to }\end{array}$ & $\begin{array}{l}\text { Architecture principles and models should ensure that public values such as equal } \\
\text { access and privacy are adhered to }\end{array}$ \\
\hline $\begin{array}{l}\text { Facilitating } \\
\text { communication }\end{array}$ & $\begin{array}{l}\text { The involvement of the administrative staff to ensure an understanding of the } \\
\text { implications }\end{array}$ \\
\hline Impact evaluation & $\begin{array}{l}\text { To evaluate the impact of the change in infrastructure and to take measures to deal } \\
\text { with them }\end{array}$ \\
\hline $\begin{array}{l}\text { Decision-making } \\
\text { support }\end{array}$ & Not identified \\
\hline Migration strategy & $\begin{array}{l}\text { This was found to deal with the limited dynamic capability and ensure incremental } \\
\text { adaptation }\end{array}$ \\
\hline
\end{tabular}

The elements presented in Table 6 allow a more comprehensive understanding of the potential effect of EA in BDA adoption and implementation. EA was not found to be important for client orientation, as BDA efforts in the tax organization were more focused on the back end. Moreover, as mentioned above, EA did not play a role in decisionmaking support as the top management made the decision to implement BDA without fully realizing the strategic 
benefit of EA. This table enables a broader view of the roles of EA and complements the narrow view that only focuses on management challenges for organizations. With an awareness of the functions of EA, as identified in our case study, whether the contribution of a certain EA function can be maximized will depend on the way EA is utilized. The internally driven and externally driven approaches in this case study reflect two roles of EA: EA as a blueprint and EA as a process.

\subsection{Lessons Learned}

The BDA efforts were largely pushed by the board, which gave limited space to the EA group to review and suggest BDA strategy. The BDA phenomenon was surrounded by uncertainties, which made it difficult to use the architecture models to determine its impact. Instead, an experimenting and learning by doing approach was adopted. This EA as a process approach enabled the creation of some BDA applications by departments and demonstrated the possibilities of BD. However, this resulted in higher costs, due to the fragmentation of initiatives and control and maintenance problems, and it was difficult to manage software and data quality. One interviewee commented that wrong data could spread like an oil slick in the organization. Data stewardship and ability to manage data is needed. Although the architecture models were little used to understand the implications, the models did provide an overview of the data sources. One interviewee emphasized the importance of EA: Data should be given only once to the government. EA should ensure that the departments reuse the data. The expectation is that once it becomes clear what BDA is and how it can be used, there will be a larger role for the architecture models to work as a blueprint. In particular, the models can be used for impact analysis and prescribing the desired infrastructure. Given the many uncertainties and lack of understanding of what BDA should look like and how the existing landscape should be adapted, EA as a blueprint was little used for BDA adoption in our case study.

The existing architecture was not ready for BDA. A move from built to last to built to change was necessary according to the interviewees. System quality was not sufficient, as data could not be easily extracted, systems were not sufficiently flexible and new functionality could not be integrated into the existing architecture. The adoption and implementation of BDA requires that the existing systems are prepared for this. The manager of the EA group stated that: EA should enable the reconfiguring of the applications and data for different purposes. In the case study, however, a new system was created at each stage. As such, an incremental strategy was followed. This approach emphasizes the roles of EA in dealing with complexity, integrating new systems into the IT landscape, facilitating reuse and communication.

Defining the starting point of BDA initiatives is a difficult endeavor. The strategy of attempting to integrate BDA into the current architecture proved not to work and, therefore, another approach was taken. Efforts were made independently of the organization, with the idea of integrating the new applications at a later stage. Nevertheless, the data was to be collected from the existing organization and an agile approach was taken by involving policymakers, administrators, domain (tax), and BDA quality and analytics experts. These teams developed the ideas for the applications, collected the data and processed the data to create new insights. These multidisciplinary teams included people from the current department and the newly founded BDA department.

The organization under study facilitated bottom-up initiatives. Although this stimulated the development of new applications and the use of BD, it also resulted in fragmentation and encountered many problems, generating limited value creation from BD. In particular, the departments only analyzed their own data, without looking at the potential to use data from other departments, which limited the value that could be created. Although the bottom-up initiatives were instrumental to the acceptance of the use of BD, they created difficulties for the distinct BDA department. They were sometimes seen as unnecessary and used different technologies. In the long run, this created integration problems. Developing an incremental migration plan was found to be key to the adoption and implementation of BDA Both applying EA as a blueprint and a process can have benefits for an organization in the adoption and implementation of BDA. A process approach allows for quick gains, but has less ability to deal with uncertainty surrounding BDA development. Adopting BDA is challenging, as substantial changes are needed. A blueprint approach should deal with the uncertainties and complexities by ensuring a configurable IT landscape, and providing an incremental approach to adapting the infrastructure step by step before the benefits of BDA can be obtained. However, the use of EA as a blueprint requires the organization to have sufficient dynamic capabilities to enable BDA implementation.

\section{Conclusions}

This research was motivated by the fact that the current literature offers few explicit insights about EA for supporting BDA adoption and implementation. The role of EA in BDA adoption and implementation in large organizations was investigated by studying the EA efforts over a prolonged period of time. The case study shows that EA can be used in various ways and that the roles of EA and the capabilities depend on the situation at hand. The context influenced the EA roles and capabilities and should be taken into account in EA research.

In the case study, initially, a bottom-up approach was initially taken to enable the creation of BDA applications; however, this strategy did not work. The complexity and fragmentation of BDA sources made the use of EA challenging. Although this strategy helped to gain an understanding of BDA and its potential for the organization, the 
departments were not able to develop the capabilities needed and the approach resulted in heterogeneity. The infrastructure could not be adapted, data quality could not be ensured, and the advantages of BDA were not realized. Subsequently, an alternative adoption strategy was introduced, with the establishment of a separate department. This department had the power and capabilities needed and did not suffer from path dependencies, quickly making use of BD. Facilities were created at lower costs and data quality could be ensured. While this was instrumental in creating BDA applications, this strategy did not, however, facilitate the adoption of BDA across the organization in general. This will require an additional step, which is still to be done in our case.

Our first research question was what are the challenges in BDA adoption and implementation for the organization?. The main challenges were fragmentation of data over many departments and organizations, dealing with privacy, lack of management capabilities of dealing with BDA adoption and no clear authority of the responsibility for BDA development and legitimacy of instating organizational change to reap the benefits of BDA.

To remove the impediments to BDA adoption and implementation, organizations need new capabilities in relation to strategy, collaboration and technology. The second research question was what are the roles and dynamic capabilities of EA in BDA adoption and implementation?. The creation of a flexible, configurable software and data infrastructure, ensuring data interoperability and enhancing collaboration among departments were found to be key capabilities. The findings suggest that large organizations that are able to adequately capture the above capabilities are more likely to make use of EA to overcome the specific challenges of BDA adoption and implementation.

The third research question was how should EA be used to facilitate BDA adoption and implementation?. The functions of EA were found in various areas, but the effective use of EA seemed to be limited in the early stages. Initially, EA was primarily used to provide an overview of the various data sources. It was only after it became clear how BDA could be implemented and used by the organization that EA started to play an important role in the creation of a flexible and configurable infrastructure, and in the assessment of BDA applications. This reveals the need to develop EA in such a way that it is able to deal with the typical characteristics of BDA. The roles and capabilities of EA changes over time and the appropriate way to use EA needs to be explored and perceived by people during the practice. This suggests that EA should not be viewed as a one size that fits, but should be customized for the various domains.

The case study reflects two main strategies of using EA in BDA adoption and implementation: as a process and as a blueprint. Although the EA as a process approach allowed for more rapid achievement of BDA benefits, it did not take into account the existing systems and thus could create integration problems in the long run. In contrast, the EA as a blueprint approach sought long-term benefits of BDA implementation. However, it also assumes that the future can be known and outlined in advance; and it needs the development of dynamic capabilities. Both approaches have their pros and cons, and we recommend that the approaches be compared in different organizations in further research.

The case study provides insights for analytical generalization to similar situations. The case study is characterized by a situation in which there are various big data sources, many stakeholders which can use big data in different ways, various kinds of analytics are used for various applications. This study has its limitations in relying on a single case study, which offers limited statistical generalizability. A consideration of more cases could provide deeper insight into the role of EA in BDA adoption and implementation in different sectors. Furthermore, we discuss the management challenges of BDA adoption in the context of large organizations. Most or even all of them might also be the challenges for small and medium enterprises. This could be subject of further research. This study has revealed that there are a number of functions for EA in BDA adoption and implementation. Further study of the potential causal relationships between EA functions and BDA development will complement current research and theory on EA benefit realization mechanisms. These studies should take into account the situation at hand and identify contextual variables.

\section{Acknowledgments}

This work is supported by the National Natural Science Foundation of China (Grant No. 71501145).

\section{References}

[1] R. Abraham, S. Aier and R. Winter, Crossing the line: Overcoming knowledge boundaries in enterprise transformation, Business \& Information Systems Engineering, vol. 57, no. 1, pp. 3-13, 2015.

[2] S. Aier, S. Weiss, R. Winter, and B. Rytz, Untangling EA's long path of becoming a partner for business transformation: The case of Swiss Federal Railways, presented at the 20th International Enterprise Distributed Object Computing Workshop (EDOCW), Vienna, Austria, September 5-9, 2016.

[3] S. Akter, S. F. Wamba, A. Gunasekaran, R. Dubey, and S. J. Childe, How to improve firm performance using big data analytics capability and business strategy alignment, International Journal of Production Economics, vol. 182, pp. 113-131, 2016. 
[4] A. Alwadain, E. Fielt, A. Korthaus, and M. Rosemann, Empirical insights into the development of a serviceoriented enterprise architecture, Data \& Knowledge Engineering, vol. 105, pp. 39-52, 2016.

[5] F. Aulkemeier, M. Schramm, M.-E. Lacob, and J. v. Hillegersberg, A service-oriented e-commerce reference architecture, Journal of Theoretical and Applied Electronic Commerce Research, vol. 11, no. 1, pp. 26-45, 2016.

[6] I. Benbasat, D. K. Goldstein and M. Mead, The case research strategy in studies of information systems, MIS Quarterly, vol. 11, no. 3, pp. 369-386, 1987.

[7] P. Bernus et al., Enterprise engineering and management at the crossroads, Computers in Industry, vol. 79, pp. 87-102, 2016

[8] P. Bernus, O. Noran and A. Molina, Enterprise architecture: Twenty years of the GERAM framework, Annual Reviews in Control, vol. 39, pp. 83-93, 2015.

[9] W. F. Boh and D. Yellin, Using enterprise architecture standards in managing information technology, Journal of Management Information Systems, vol. 23, no. 3, pp. 163-207, 2006.

[10] R. S. Boyd and S. Geiger, Enterprise architecture and information technology acquisition management, Journal of Enterprise Architecture, vol. 6, no. 4, pp. 43-47, 2010.

[11] R. V. Bradley, R. M. E. Pratt, and T. A. Byrd, The role of enterprise architecture in the quest for IT value, MIS Quarterly Executive, vol. 10, no. 2, pp. 73-80, 2011

[12] R. V. Bradley, R. M. E. Pratt, T. A. Byrd, C. N. Outlay, and D. E. Wynn, Enterprise architecture, IT effectiveness and the mediating role of IT alignment in US hospitals, Information Systems Journal, vol. 22, no. 2, pp. 97-127, 2012.

[13] A. Carmeli and A. Tishler, The relationships between intangible organizational elements and organizational performance, Strategic Management Journal, vol. 25, no. 13, pp. 1257-1278, 2004.

[14] C. L. P. Chen and C.-Y. Zhang, Data-intensive applications, challenges, techniques and technologies: A survey on Big Data, Information Sciences, vol. 275, pp. 314-347, 2014

[15] K. Chen, Y.-H. Hu and Y.-C. Hsieh, Predicting customer churn from valuable B2B customers in the logistics industry: A case study, Information Systems and e-Business Management, vol. 13, no. 3, pp. 475-494, 2015.

[16] D. J. Collis, Research note: How valuable are organizational capabilities?, Strategic Management Journal, vol. 15, no. Winter, pp. 143-152, 1994.

[17] C. K. Davis, Beyond data and analysis, Communications of the ACM, vol. 57, no. 6, pp. 39-41, 2014.

[18] G. Doucet, J. Gøtze, P. Saha, and S. Bernard, Coherency management: Using enterprise architecture for alignment, agility, and assurance, Journal of Enterprise Architecture, vol. 4, no. 2, pp. 9-20, 2008.

[19] D. Drewer and V. Miladinova, The BIG DATA challenge: Impact and opportunity of large quantities of information under the Europol Regulation, Computer Law \& Security Review, vol. 33, no. 3, pp. 298-308, 2017.

[20] K. M. Eisenhardt and J. A. Martin, Dynamic capabilities: What are they?, Strategic Management Journal, vol. 21 , no. 10-11, pp. 1105-1121, 2000.

[21] R. El-Gazzar, E. Hustad and D. H. Olsen, Understanding cloud computing adoption issues: A Delphi study approach, Journal of Systems and Software, vol. 118, pp. 64-84, 2016.

[22] O. Erol, B. J. Sauser and M. Mansouri, A framework for investigation into extended enterprise resilience, Enterprise Information Systems, vol. 4, no. 2, pp. 111-136, 2010.

[23] R. Foorthuis, M. Van Steenbergen, S. Brinkkemper, and W. A. G. Bruls, A theory building study of enterprise architecture practices and benefits, Information Systems Frontiers, vol. 18, no. 3, pp. 541-564, 2016.

[24] Gartner. (2016) Gartner IT glossary - enterprise architecture. Gartner. [Online]. Available: http://www.gartner. com/it-glossary/enterprise-architecture-ea/

[25] S. Giest, Big data for policymaking: fad or fasttrack?, Policy Sciences, vol. 50, no. 3, pp. 367-382, 2017.

[26] Y. Gong and M. Janssen, Enterprise architectures for supporting the adoption of big data, presented at the 18th Annual International Conference on Digital Government Research, Staten Island, NY, USA, June 7-9, 2017.

[27] Y. Gong and M. Janssen, The value of and myths about enterprise architecture, International Journal of Information Management, vol. 46, pp. 1-9, 2019.

[28] M. Gupta and J. F. George, Toward the development of a big data analytics capability, Information \& Management, vol. 53, no. 8, pp. 1049-1064, 2016

[29] W. Hofman and M. Rajagopal, A technical framework for data sharing, Journal of Theoretical and Applied Electronic Commerce Research, vol. 9, no. 3, pp. 45-58, 2014

[30] J. J. P. Jansen, F. A. J. Van den Bosch and H. W. Volberda, Exploratory innovation, exploitative innovation, and ambidexterity: The impact of environmental and organizational antecedents, Schmalenbach Business Review, vol. 57, no. 4, pp. 351-363, 2005

[31] M. Janssen, Framing enterprise architecture: A meta-framework for analyzing architectural efforts in organizations, in Coherency Management: Architecting the Enterprise for Alignment, Agility and Assurance (G. Doucet, J. Gøtze, P. Saha, and S. Bernard, Eds.). Bloomington: Authorhouse, 2009, pp. 107-126.

[32] M. Janssen, Sociopolitical aspects of interoperability and enterprise architecture in e-government, Social Science Computer Review, vol. 30, no. 1, pp. 24-36, 2012.

[33] M. Janssen, H. van der Voort and A. Wahyudi, Factors influencing big data decision-making quality, Journal of Business Research, vol. 70, pp. 338-345, 2017.

[34] G.-H. Kim, S. Trimi and J.-H. Chung, Big data applications in the government sector: A comparative analysis among leading countries, Communications of the ACM, vol. 57, no. 3, pp. 78-85, 2014

[35] B. Klievink, B.-J. Romijn, S. Cunningham, and H. de Bruijn, Big data in the public sector: Uncertainties and readiness, Information Systems Frontiers, vol. 19, no. 2, pp. 267-283, 2017.

[36] M. Lankhorst, Enterprise Architecture at Work: Modelling, Communication and Analysis, 3nd ed. Berlin Heidelberg: Springer, 2013. 
[37] L.-S. Lê and A. Wegmann, Hierarchy-oriented modeling of enterprise architecture using reference-model of open distributed processing, Computer Standards \& Interfaces, vol. 35, no. 3, pp. 277-293, 2013.

[38] I. Lee, Big data: Dimensions, evolution, impacts, and challenges, Business Horizons, vol. 60, no. 3, pp. 293-303, 2017.

[39] Å. Lindström, P. Johnson, E. Johansson, M. Ekstedt, and M. Simonsson, A survey on ClO concerns-do enterprise architecture frameworks support them?, Information Systems Frontiers, vol. 8, no. 2, pp. 81-90, 2006.

[40] M. Maciejewski, To do more, better, faster and more cheaply: Using big data in public administration, International Review of Administrative Sciences, vol. 83, no. 1S, pp. 120-135, 2017.

[41] D. $\varnothing$. Madsen and T. Stenheim, Big data viewed through the lens of management fashion theory, Cogent Business \& Management, vol. 3, no. 1, 2016.

[42] A. Martin, D. Dmitriev and J. Akeroyd, A resurgence of internest in information architecture, International Journal of Information Management, vol. 30, pp. 6-12, 2010.

[43] A. McAfee and E. Brynjolfsson, Big data: The management revolution, Harvard Business Review, no. 2012, 2012.

[44] I. Mergel, R. K. Rethemeyer and K. Isett, Big data in public affairs, Public Administration Review, vol. 76, no. 6, pp. 928-937, 2016.

[45] P. Närman, H. Holm, D. Höök, N. Honeth, and P. Johnson, Using enterprise architecture and technology adoption models to predict application usage, Journal of Systems and Software, vol. 85, no. 8, pp. 1953-1967, 2012.

[46] E. Niemi and S. Pekkola, Using enterprise architecture artefacts in an organisation, Enterprise Information Systems, vol. 11, no. 3, pp. 313-338, 2017.

[47] E. I. Niemi and S. Pekkola, Enterprise architecture benefit realization: Review of the models and a case study of a public organization, The Data Base for Advances in Information Systems, vol. 47, no. 3, pp. 55-80, 2016.

[48] J. M. Nogueira, D. Romero, J. Espadas, and A. Molina, Leveraging the Zachman framework implementation using action - research methodology - a case study: Aligning the enterprise architecture and the business goals, Enterprise Information Systems, vol. 7, no. 1, pp. 100-132, 2013.

[49] T. A. Pardo, T. Nam and G. B. Burke, E-government interoperability: Interaction of policy, management, and technology dimensions, Social Science Computer Review, vol. 30, no. 1, pp. 7-23, 2012

[50] A. Popovič, R. Hackney, R. Tassabehji, and M. Castelli, The impact of big data analytics on firms' high value business performance, Information Systems Frontiers, vol. 20, no. 2, pp. 209-222, 2018.

[51] H. A. Proper, Enterprise architecture: Informed steering of enterprises in motion, presented at the 15th International Conference on Enterprise Information Systems (ICEIS 2013), Angers, France, July 4-7, 2013.

[52] D. Romero and F. Vernadat, Enterprise information systems state of the art: Past, present and future trends, Computers in Industry, vol. 79, pp. 3-13, 2016.

[53] J. W. Ross, P. Weill and D. Robertson, Enterprise Architecture as Strategy: Creating a Foundation for Business Execution. Boston: Harvard Business Review Press, 2006.

[54] H. Safari, Z. Faraji and S. Majidian, Identifying and evaluating enterprise architecture risks using FMEA and fuzzy VIKOR, Journal of Intelligent Manufacturing, vol. 27, no. 2, pp. 475-486, 2016.

[55] M. M. Sayegh and K. A. Barakat, Privacy and disclosure: Customer attitudes towards the use of big data by retail companies, International Journal of Security and Its Applications, vol. 12, no. 3, pp. 11-18, 2018.

[56] C. Schmidt and P. Buxmann, Outcomes and success factors of enterprise IT architecture management: Empirical insight from the international financial services industry, European Journal of Information Systems, vol. 20, no. 2, pp. 168-185, 2011.

[57] G. Shanks, M. Gloet, I. A. Someh, K. Frampton, and T. Tamm, Achieving benefits with enterprise architecture, The Journal of Strategic Information Systems, vol. 27, no. 2, pp. 139-156, 2018.

[58] D. Simon, K. Fischbach and D. Schoder, Enterprise architecture management and its role in corporate strategic management, Information Systems and e-Business Management, vol. 12, no. 1, pp. 5-42, 2014.

[59] U. Sivarajah, M. M. Kamal, Z. Irani, and V. Weerakkody, Critical analysis of big data challenges and analytical methods, Journal of Business Research, vol. 70, pp. 263-286, 2017.

[60] H. A. Smith and R. T. Watson, The jewel in the crown - enterprise architecture at chubb, MIS Quarterly Executive, vol. 14, no. 4, pp. 195-209, 2015

[61] S. H. Spewak, Enterprise Architecture Planning. Developing a Blueprint for Data, Applications and Technology. New York: John Wiley, 1992.

[62] T. Tamm, P. B. Seddon, G. Shanks, P. Reynolds, and K. Frampton, How an Australian retailer enabled business transformation through enterprise architecture, MIS Quarterly Executive, vol. 14, no. 4, pp. 181-193, 2015.

[63] D. J. Teece, G. Pisano and A. Shuen, Dynamic capabilities and strategic management, Strategic Management Journal, pp. 509-533, 1997.

[64] The Open Group, The Open Group Architecture Framework (Version 9.1), 's-Hertogenbosch: Van Haren Publishing, 2011.

[65] L. Van Zoonen, Privacy concerns in smart cities, Government Information Quarterly, vol. 33, no. 3, pp. 472-480, 2016.

[66] A. Vargas, A. Boza, S. Patel, D. Patel, L. Cuenca, and A. Ortiz, Inter-enterprise architecture as a tool to empower decision-making in hierarchical collaborative production planning, Data \& Knowledge Engineering, vol. 105, pp. 5-22, 2016.

[67] A. Vargas, L. Cuenca, A. Boza, I. Sacala, and M. Moisescu, Towards the development of the framework for inter sensing enterprise architecture, Journal of Intelligent Manufacturing, vol. 27, no. 1, pp. 55-72, 2016. 
[68] Z. Wang and Q. Yu, Privacy trust crisis of personal data in China in the era of big data: The survey and countermeasures, Computer Law \& Security Review, vol. 31, no. 6, pp. 782-792, 2015.

[69] A. L. Washington, Government information policy in the era of big data, Review of Policy Research, vol. 31, no. 4, pp. 319-325, 2014.

[70] E. W. Welch, M. K. Feeney and C. H. Park, Determinants of data sharing in U.S. city governments, Government Information Quarterly, vol. 33, no. 3, pp. 393-403, 2016.

[71] R. Winter, C. Legner and K. Fischbach, Introduction to the special issue on enterprise architecture management, Information Systems and e-Business Management, vol. 12, no. 1, pp. 1-4, 2014.

[72] S. G. Winter, Understanding dynamic capabilities, Strategic Management Journal, vol. 24, no. 10, pp. 991-995, 2003.

[73] R. K. Yin, Case Study Research: Design and methods. Newbury Park, CA: Sage publications, 1989.

[74] F. Zandi and M. Tavana, A fuzzy group multi-criteria enterprise architecture framework selection model, Expert Systems with Applications, vol. 39, no. 1, pp. 1165-1173, 2012. 